\title{
Ser e não ser, essa é a missão: ontologia das regras em jogos de computador ${ }^{1}$
}

\author{
Ivan Mosca \\ Doutor; University of Torino, Torino, Itália \\ ivan.mosca@gmail.com \\ Tradução: Gabriela Kurtz \\ Pontifícia Universidade Católica do Rio Grande do Sul, Porto Alegre, RS, Brasil \\ Universidade Federal do Rio Grande do Sul \\ gabriela@sidicom.com.br \\ Revisão de tradução: Suely Fragoso \\ Universidade Federal do Rio Grande do Sul, Porto Alegre, RS, Brasil \\ suelyfragoso@ufrgs.br
}

\section{Resumo}

Este artigo pretende demonstrar que jogos não podem ser analisados como sistemas de regras. As ferramentas teóricas disponíveis na Ontologia Social de John Searle podem ser aplicadas aos Game Studies, especialmente na análise das regras. De acordo com a Ontologia Social, tanto as regras quanto os jogos podem ser definidos como objetos que dependem dos sujeitos, mas o processo de constituição de cada um é diferente. A maior parte dos estudiosos dos Game Studies explicam os jogos de computador como sistemas de regras, mas normalmente não há regras em jogos baseados em computador. Jogadores de computador não obedecem nem seguem regras, e nem designers nem programadores prescrevem regras: em vez disso, eles criam affordances que usuários podem usar para jogarem ou não. De fato, a constituição de um jogo depende da maneira com a qual os jogadores significam sua atividade, o que requer consciência completa e a liberdade para definir algo como um jogo ou não. Finalmente, o artigo fornece uma categorização dos jogos que fazem uso de regras (apenas alguns jogos de computador estão incluídos), uma categorização dos jogadores que fazem uso de regras, e uma categorização de teorias de games que se referem a regras.

\footnotetext{
${ }^{1}$ Originalmente publicado em Proceedings of Philosophy of Computer Games Conference, Atenas, 2011. Quando a revista Intexto, na pessoa da Profa. Suely Fragoso, me pediu permissão para tradução do artigo em português brasileiro, aproveitei a ocasião para preencher o artigo, melhorando suas expressões línguísticas e inserindo algumas palavras aqui e ali. A despeito destas mudanças pequenas, a estrutura, a tese e os limites do artigo são os mesmos que o original.
} 


\section{Palavras-chave}

Regras. Ontologia Social. Jogos de Computador. Estudos de Jogos.

\section{Introdução}

De acordo com David Myers (2006, p. 47), "jogos, como a literatura, usam signos convencionalmente e símbolos de formas não convencionais". Nós sabemos que a literatura, diferentemente da pintura, é explícita em seu conteúdo; games, no entanto, são tanto explícitos quanto não explícitos em seu conteúdo, então sua propriedade distintiva deve ser buscada em outro lugar. Alguns estudiosos dos Game Studies argumentam que os games, diferentemente de outras mídias, evidenciam a forma que os jogadores deveriam proceder para interagir com eles através das regras.

Mesmo assim, nem todos os games tem regras, em vez disso poderíamos dizer que todos os games tem algumas formas de interação. Isso, no entanto, também é o caso da literatura, como Wolfgang Iser e a Escola Constance mostraram: o leitor sempre interage com os significados de um trabalho literário. Certamente, a interação simbólica de Iser está presente nos games, mas os jogadores interagem também de forma material com os elementos estruturais do jogo. 0 que é então mais importante na estrutura de um game: regras, interação ou outra coisa?

Para responder essa pergunta, eu proponho incluir no debate dos Games Studies algumas ferramentas teóricas disponíveis no projeto de uma Ontologia Social de John Searle, que se torna especialmente útil para a análise das "regras".

\section{Social Ontology Project}

Antes da publicação da versão original deste artigo (2011), eu encontrei a aplicação da Ontologia Social de John Searle $(1995 ; 2010)$ apenas uma vez nos Game Studies, por Sebastian Deterding (2009). Desde então, a ontologia social tem sido usada em várias outras pesquisas em games, porque ela pode facilmente explicar o papel dos jogos em nossa sociedade. A ontologia social lida com objetos que existem na medida em que pessoas acreditam que eles existam, como instituições, contratos, leis do Estado, dinheiro, casamento e games. Esses objetos não são reduzidos a meros pensamentos porque, uma vez 
gerados, eles não podem ser alterados por um sujeito único. 0 valor de uma conta, por exemplo, depende da crença do sujeito, porém esse indivíduo sozinho não pode modificar seu valor. Searle descreve a forma lógica dessa designação função-status:

«X (um objeto físico) conta como Y (uma função-status) em C (um contexto)».2

Exemplo: "esse pedaço de papel conta como uma nota bancária em uma troca econômica".

Muitos ontologistas sociais pensam que os games são modelos formais e históricos de objetos sociais. De modo inverso, objetos sociais podem ser utilizados como modelos formais para analisar games: usando uma função-status é possível considerar uma Xvassoura como um Y-cavalo em um C-jogo. Quando o jogo termina, o Y-cavalo volta a ser uma X-vassoura.

Identidade, um tipo de doppelganger linguístico de entidade, é a função-status mais importante da realidade social. Em um mundo lúdico, as identidades se sobrepõem, dobram e se dividem em muitas formas: a função-status pessoal de "John" em um contexto lúdico como um MMORPG, se sobrepõe com a função-status do personagem "Argramar o Ogro".

Searle, referindo-se a trabalhos anteriores por Rawls (1955), Znamierowski (1924), Reinach (1913), e outros filósofos, liga a função-status à linguagem, explicando seu funcionamento em termos de "regras constitutivas", por exemplo, regras que precedem o objeto que elas regulam (diferentemente de "regras regulativas", que as seguem). Objetos sociais como dinheiro, games, casamentos, propriedade privada e leis do Estado são geradas por regras constitutivas.

\section{0 que é uma regra?}

Aprender uma atividade normalmente ocorre em conformidade com algumas regras (por exemplo: instruções sobre "como beijar"), mas isso não significa que essa atividade consiste na complacência com regras. Embora isso possa ser descrito utilizando regras, beijar não é uma atividade regulada, exatamente como rasgar uma folha de grama, orbitar ao redor do sol e jogar Second Life (ROSEDALE, 2003).

A relação entre jogos e regras é uma das mais citadas, mas menos estudadas do campo dos Game Studies. Uma forma de abordar esse tópico pode ser encontrada olhando para as 
patentes dos jogos. Muitos jogos tem uma marca registrada onde os direitos são protegidos de várias maneiras, mas se é possível patentear um jogo como uma sequência de signos precisa (como o código), não é possível patentear uma regra ou uma mecânica única (ex.: a principal mecânica de Jogos de Tiro em Primeira Pessoa): o que é patenteável são apenas os meios técnicos para jogar, como configurações de hardware e software. Em vez disso, regras dependem do sujeito para existirem, e os estados intencionais não são patenteáveis como se fossem objetos.

Isso nos leva a evitar considerar regras como objetos. Mais vantajoso é entendermos as regras como funções-status atribuídas a elementos linguísticos que dependem de estados intencionais, que são sempre ligados a crença ou descrença. Alguém pode seguir uma regra se acredita que uma certa ação deveria (ou deve) ser feita. É uma questão de "dever" em vez de "ser": o sujeito poderia acreditar que uma regra é um objeto em si, mas isso não transforma uma regra em um objeto, como acreditar em Zeus não significa causar sua existência em si. Os objetos de crença existem apenas dentro dos estados da mente de sujeitos. Se tais objetos mantêm um referente (na realidade externa) então a crença é verdadeira, do contrário, ela é falsa. 0 que transforma um estado intencional único em um objeto social é seu compartilhamento entre pessoas diferentes. Portanto, uma regra é um objeto apenas se compartilhado por mais de uma mente subjetiva.

Um tipo particular de estado intencional relacionado a games é o estado ficcional (WALTON, 1978;1990). Para fazer crer que Ofélia e Hamlet se tornaram tolos, mas apenas o anterior cometeu suicídio, isso não requer nenhuma crença, mas requer sua contradição, uma descrença:

Objeto social: crença

VS

Objeto ficcional: descrença

Por meio do "faz-de-conta", o sujeito não apenas acredita na objetividade das funçõesstatus que ele atribui ao objeto: a função-status é então "intransitiva".

Função-status: transitiva

VS

Função-status: intransitiva

De acordo com Searle, objetos sociais dependem da linguagem. Outro filósofo que investigou questões linguísticas, Ludwig Wittgenstein, descreve a linguagem como uma rede de diferentes e muitas vezes incompatíveis "jogos linguísticos". A ontologia social descreve 
jogos linguísticos como a principal estrutura da realidade social e consequentemente da irrealidade ficcional de jogos. Nós não podemos considerar todo objeto social como um jogo, porque o que caracteriza um jogo como tal, ou o gameness $^{3}$ de um jogo, não pode ser definido como um objeto social em si mesmo. Inspirado nas produções de Bateson (1955;1956), Deterding (2009) se refere à o que caracteriza um jogo (o gameness) como um gameframe, um ponto de vista cultural e psicológico particular que, aplicado a qualquer objeto, o define como uma atividade de jogo. Tudo pode ser um jogo, usando as lentes especiais do gameness.

O Social Ontology Project não foi projetado para investigar (apenas) games, mas pode ser útil para entender a différance ${ }^{4}$ entre uma função-status (acreditada como objetiva) e uma ficção-status (não realmente acreditada como objetiva) reside no ponto de vista subjetivo. A auto-referência do sujeito é o processo principal da atividade de faz-de-conta e do jogo que a segue. Como também Tavinor (2009a, p. 94) escreveu, "videogames modernos são máquinas de ficção".

No entanto, nós precisamos enfatizar o fato claro de que games não são feitos apenas pela ficção, porque eles envolvem (pelo menos) também interação, que definimos aqui como um processo de ação e feedback entre jogador e jogador e/ou entre jogador e game. A manipulação realizada pelo jogador é direcionada tanto no nível dos significados (ISER, 1999 [1976]) mas também e especialmente no nível das affordances materiais (GIBSON, 1979). A dimensão lúdica é um tipo de "ficção explícita e interativa", considerando atividades ficcionais como aquelas que, tornando explícita a separação do signo da realidade, se diferencia de uma simples mentira.

\section{Objetos sujeito-dependentes}

Ainda Brenda Laurel (1991, p. 117) e Janet Murray (1998, p. 126) salientaram a centralidade do sujeito na estrutura de um game. Os assim chamados games zero-jogador, como o algoritmo fractal auto reprodutor chamado The Game of Life (GARDNER, 1970), não envolve o gameness. 0 dilema do prisioneiro, fora de uma simulação, não é lúdico, mas uma tortura dolorosa. Laurel considera o sujeito como uma parte central dos games por conta de

\footnotetext{
${ }^{3}$ Nota da tradutora: a palavra foi mantida em inglês pois corresponde a um conceito desenvolvido pelo autor para o qual não foi encontrado correspondente na língua portuguesa.

${ }^{4}$ Nota da tradutora: o autor está fazendo referência ao conceito na obra de Derrida. Para aprofundamento, ver Jacques Derrida, Gramatologia. São Paulo: Perspectiva, 1973.
} 
sua natureza interativa, enquanto Murray considera o sujeito como central nos games por conta da necessidade de sua interpretação e atividade ficcional. 0 jogador está ciente de seu poder direto e total dos status fictícios que constituem seu mundo lúdico: essa consciência divide a ficção-status de uma atividade de jogo da função-status de atividades sociais sérias. Assim sendo, um jogo de computador é um jogo apenas e somente se o jogador tem a intenção que isso seja um jogo. Trabalhando como um testador de games, eu joguei apenas nos primeiros dias de um novo projeto: depois, era apenas trabalho.

Mudando a atenção para o sujeito é necessário porque a fenomenologia emerge como um dado: como Wittgenstein (1953) detectou, não há propriedades intrínsecas e compartilhadas para todos os jogos. 0 jogador está sempre no centro do jogo, mesmo se ele tem um papel separado dos eventos planejados ou se ele move uma série de avatares que não o representam, como no xadrez, jogos de estratégia em tempo real, God Games ${ }^{5}$. Games são sistemas criados para usuários: para cria-los, alguns meios são mais adequados que outros, mas a chave não é a sintática dos meios, mas a modalidade usada pelo jogador para interagir com tais meios. 0 que é e o que não é lúdico é questão definida pela cultura ou psicologia e não pelos dispositivos tecnológicos. Por exemplo, antes de encontrar pessoas que brincaram com simuladores de bondes, eu nunca havia pensado que eles poderiam ser encarados como games, especialmente nos casos em que os jogadores não tem papéis interativos: no modo passageiro de um simulador desse tipo, o único entretenimento consiste em ver se o modelo virtual da minha parada de trem é realista, com poucas chances de sair da parada depois disso. No entanto, esse épico cotidiano é considerado lúdico no Japão, onde tem sido um gênero prolífico por décadas. Há aqueles que jogam com fantoches, e aqueles que jogam com roleta-russa, aqueles que jogam sozinhos, e aqueles que jogam com outros, há aqueles que jogam desafiando a melhor inteligência artificial no xadrez e aqueles que jogam apenas clicando no botão "Estou com sorte" do Google. É difícil detectar algo que todas essas atividades compartilham, porque elas dependem da intencionalidade do sujeito. De acordo com Consalvo (2007, p. 2) o jogador é central para o entendimento dos games, e conforme Galloway (2006, p. 5), "tanto a máquina quanto o operador trabalham juntos em um relacionamento cibernético" para constituir o game.

Um tipo de revolução Copérnica nos Game Studies pode ser feita focando mais no sujeito do que no objeto, ou focando melhor na relação entre sujeito e objeto. Isso está

\footnotetext{
5 Nota da Tradutora: God Games são jogos em que o jogador está situado em uma posição externa e superior aos acontecimentos, de forma análoga a uma entidade com poderes divinos.
} 
estritamente ligado ao estudo do qualia ${ }^{6}$ endossado pelas ciências cognitivas, cujo ancestral mais importante pode ser encontrado em Galileo Galilei (2000 [1623]), para quem os objetos tem dois tipos de propriedades: as primárias (como massa, dimensões espaciais e formato), que são características dos objetos em relação a outros objetos, e as secundárias (como cor ou gosto), que são características dos objetos em relação aos sujeitos. As propriedades dos games podem ser interpretadas como secundárias, porque elas derivam da interação entre objeto e sujeito. A versão contemporânea de "propriedades secundárias" é a noção similar de "affordances", introduzida por James Gibson (1979) para identificar a propriedade que um objeto tem apenas em relação ao outro objeto específico que possa ser descrito como sujeito.

Durante uma discussão pessoal sobre este tópico, John Richard Sageng levantou uma objeção baseado em que todo artefato exibe um tipo de dependência sobre um sujeito. Ex: selos dependem "de crenças, intenções e usos dos seus criadores. Apesar deste tipo de dependência, ainda faz sentido tratar selos como objetos ou tendo propriedades objetivas (feito na China, vale 5 centavos, segunda edição, pré-guerra civil, etc.) e sendo objetos em vez de estados mentais". A objeção perspicaz de Sageng apontou o problema: o que estou tentando examinar está conectado às propriedades secundárias de artefatos que dependem do sujeito. 0 formato de um selo depende de suas propriedades primárias físicas (objetivas), sua cor depende tanto de suas propriedades físicas quanto em sua relação com meus olhos particularmente, enquanto as propriedades "feito na China", "valendo 5 centavos" e "período pré-guerra civil" são todos fatos institucionais, cuja constituição e suporte dependem de uma cadeia e de um compartilhamento de crenças subjetivas.

A perigosa ligação entre jogos e linguagem é enfatizada também pelo anteriormente citado Gregory Bateson (1955; 1956), que considera o jogo não como uma atividade, mas como uma estrutura de comunicação, uma meta-mensagem negativa. De acordo com Bateson, jogar é "representar a representação de X" sem representar X, um tipo de simulacro Baudrillardiano. A negação lógica pode ser considerada como a base formal das atividades de games, que são, por sua vez, a base ontogenética, e até filogenética de toda a linguagem. Para uma descrição da realidade primária e crível ("X não é Y"), se segue uma secundária, lúdica e de faz-de-conta ("X não é X"), que então é seguida por uma simbolização linguística terciária ("X é Y"). Neste processo, a presença da prescrição "deveria” não é necessária. Para Searle (2010), a prescrição "deveria" apenas emerge em uma quarta fase,

${ }^{6}$ Qualia é um termo específico da filosofia que designa o que é irredutivelmente subjetivo em uma experiência. 
onde o "X é Y" esconde um "X deveria ser Y", um movimento que conduz à constituição de uma instituição. Prescrições não estão no centro de propósitos ou estruturas lúdicas. De acordo com Bateson, a estrutura lúdico-linguística distingue o símbolo-Y da coisa-X: por conta disso o esquizofrênico, que não distingue o signo do referente, é sempre sério e nunca brinca, mesmo que utilize um estilo lúdico de comunicação.

Por conta disso, é possível distinguir uma abordagem ontológica onde o game (G) é um objeto ("X conta como G em C") e uma abordagem formal onde o game (G) é uma estrutura ("X conta como Y em G"). Nessa segunda abordagem o jogo é um modo que pode ser aplicado a qualquer objeto. De fato, o que é um jogo em uma comunidade não é necessariamente um jogo em outras. Seguindo a abordagem formal, Vossen (2004) divide "Jogar" como um modo de faz-de-conta lúdico e "Jogo" como um objeto baseado em regras. De acordo com Vossen, há duas teorias principais: a primeira descreve "Jogo" como o resultado de um contínuo que começa pelo "Jogar”, e a segunda descreve um pulo ontológico de "Jogar" para "Jogo", um pulo que normalmente é atribuído às regras. A teoria de Searle pode ser integrada neste segundo grupo teórico, porque ele considera as regras constitutivas como a principal estrutura de toda a realidade social. 0 problema com esse grupo teórico é que há muitos "Jogos" que não são governados por regras, por exemplo, jogos de computador (cujo subtipo nomeado "videogame", baseado em telas visuais, é o mais difundido).

\section{Erros típicos}

Muitos estudiosos dos games hipostatizam a relação entre regras e jogos de computador, mas é muito difícil encontrar tal relação. De acordo com Miguel Sicart (2009) "o nível semântico comunica as regras por meio de metáforas". Para Patrícia Greenfield (1984), a diferença entre os jogos tradicionais e os jogos de computador é que nos de computador as regras não estão declaradas antes de começar a jogar, em vez disso elas são descobertas jogando. Jesper Juul (2005, p. 58) escreve que "regras especificam limitações e affordances. Elas proíbem jogadores de realizar ações [...] mas elas também adicionam significado às ações permitidas e isso proporciona aos jogadores ações significativas que não estavam disponíveis de outra maneira; regras conferem estrutura aos jogos". Greg 
Lastowka (2009, p. 16) afirma que os EULAs ${ }^{7}$ são manuais de games e que "as regras do World of Warcraft não são tão diferentes das regras que governam o gridirion ${ }^{8}$, o campo de golfe, o campo de baseball e o tabuleiro de jogo". John Richard Sageng (2009, p. 2,) afirma que "jogos normalmente contam com a combinação da ação governada por regras e representação. 0 papel da computação nos jogos de computador é o de facilitar ou substituir regras por ações". Fernandez Vara (2009, p.63) declara que "regras são reforçadas pelo código do(s) programa(s) que faz(em) o jogo", e "as mecânicas de jogo são um subconjunto das regras do jogo no geral [...] e são seguidas pelo computador como um executante, enquanto que as mecânicas de jogo são aquelas disponíveis para o jogador como ator". Muitos autores associam as regras a coerções, da mesma forma que associam regras a simulação, e frequentemente atribuem ao código do programa a noção de "sistema de regras".

Relendo nessa perspectiva as pesquisas em games, mesmo aquelas que especificamente lidam com regras, como a de Salen e Zimmerman, nós podemos notar a ausência de uma diferenciação fundamental entre uma vasta série de entidades e processos: a descrição abstrata do código do programa e do funcionamento material de um computador, a tela e as affordances da interface, as regras regulativas e as constitutivas, as regras prescritivas e descritivas. Desse ponto de vista, as teorias e explicações de jogos que são baseadas em regras não são satisfatórias também para a indústria, que certamente utiliza categorias ingênuas, mas úteis (como aquelas de Bartle) ao invés de teorias sofisticadas, porém inúteis. Para entender a distância entre a teoria e a prática do game design, podemos considerar a abordagem de Sicart, que combina regras regulativas (que seguem a ação) com regras constitutivas (que precedem a ação) para afirmar que se as mecânicas do jogo dizem respeito à interação com o estado do jogo, as regras, por sua vez, proporcionam um espaço de possibilidade onde a interação é possível, regulando também a transição entre os estados. Dessa forma, para Sicart, as regras são modeladas pela agência, enquanto as mecânicas são modeladas para criar agência. Isso nos leva imediatamente a identificar as entidades que Sicart simplesmente nomeou como "regras" como sendo as regras descritivas, como aquelas da física.

Para resolver parcialmente a confusão disseminada nos game studies, podemos recorrer a outras disciplinas filosóficas, como, por exemplo, a lógica deôntica estudada por

\footnotetext{
7 Do inglês: End-user license agreement, ou acordo de licença com o usuário final. ${ }^{8}$ Nota da tradutora: Futebol Americano.
} 
Georg Henrik Von Wright e Antonio Conte (1985), que afirmam que as regras descritivas fazem uso da normatividade para comunicar a um sujeito "como um objeto funciona em um sistema". Por outro lado, as regras prescritivas prescrevem um comportamento a um sujeito que, enquanto não sendo modalmente forçado a obedecer, pode escolher seguir ou não a regra. Como afirmado por Rawls (1955), um manual de instruções ou um livro de receitas dedicado a transmitir um conhecimento ou uma técnica pode formalizar uma atividade que não é governada por regras (como beijar ou cozinhar uma pizza) ao representá-la como um sistema de regras. As regras descritivas de uma receita são produzidas pela indução observacional de um estado das coisas. As regras prescritivas, do contrário, são sempre e apenas impostas pelo sujeito a si mesmo ou a outros sujeitos, eles não podem derivar da observação do estado das coisas, assim como não é possível fazer uma indução de "deveria" a partir de "é" (HUME, 2001 [1739]). Regras prescritivas são sempre, e apenas, relacionadas à intencionalidade subjetiva: pedras não obedecem regras, exatamente como computadores também não o fazem: para seguir uma regra é necessário ser livre para não segui-la. Regras podem ser concebidas como objetos apenas por um ponto de vista interno, porque elas não tem poder causal sem a mediação de um sujeito. As regras descritivas usadas com o propósito científico de prever futuros comportamentos de um fenômeno regular não podem ser assumidas como uma descrição científica das regras em si. Cada explicação que coloca regras como causas sem incluir a concordância subjetiva, não explica realmente nenhum fenômeno.

\section{Personagem não-jogável}

As "instruções" ou "comandos" inseridos em um computador não são regras, nem para o computador nem para o usuário. Um computador não pode desobedecer esses comandos, logo, ele não pode entendê-los como regras para seu "comportamento". Comandos e instruções inseridas por um programador operam como qualquer fato bruto, mecânica e deterministicamente, para causas e efeitos. Regras prescritivas são ontologicamente necessárias para explicar os comportamentos de jogadores de xadrez, enquanto para explicar o comportamento de computadores nós não precisamos necessariamente de regras, que podem ser usadas ou não apenas como ferramentas epistemológicas.

Objetos como computadores (e pedras) não podem seguir regras, enquanto sujeitos podem fazer isso apenas se eles explicitamente sabem e escolhem segui-las. Não há algo 
como jogadores involuntários; em RPGs eles são nomeados NPCs (personagens nãojogáveis, do inglês non-playing characters). Durante o famoso desafio de xadrez entre o campeão humano Garry Kasparov e o supercomputador Deep Blue, este último não tinha possibilidade de trapacear, e ele nunca jogou. Apenas um computador filosófico e supercientífico que usasse um nível semântico durante o processamento de dados poderia jogar um jogo, ou seja, atribuir significado aos meios. Um computador real, ao contrário, é uma entidade incapaz de pretender e consentir, não por lei, mas por fato.

Jogadores apenas jogam se eles sabem que estão jogando. Jogar é uma atividade subjetiva que depende do estado intencional. Você não pode descobrir que está jogando ou não, e você pode apenas começar ou parar de jogar. Ninguém pode demonstrar que você está jogando ou não contra seu verdadeiro ponto de vista. No final do filme Vidas em Jogo (Fincher, 1997), o protagonista não descobre que ele estava jogando, mas ele descobre que as outras pessoas que ele encontrou durante o filme estavam, e que elas não estavam levando a sério como ele. Jogos não tem propriedades objetivas em si mesmos, mas apenas uma vasta variedade de concepções em uma variedade de visões antropológicas e psicológicas. A Ontologia está aqui para mostrar isso.

\section{Questões mágicas}

Nós temos que entender que nem tudo que é governado por regras é um jogo (ex.: burocracia não é um jogo) e que nem todos os jogos tem regras ${ }^{9}$. Acima de tudo, jogos com regras não existem apenas como manuais, eles precisam ser jogados para existirem, do mesmo modo como não há União Soviética sem alguém que siga a Constituição Soviética (alguma entre as de 1924, 1936 e 1977). Em muitos jogos de tabuleiro, esportes, interpretação de papéis, jogos tradicionais ou improvisados, as regras prescritivas têm o papel de constituir a atividade lúdica. De modo inverso, em jogos de computador é difícil detectar algumas regras prescritivas direcionadas à restrição do comportamento do

\footnotetext{
${ }^{9}$ Em Mosca (2017) eu expresso a questão dessa maneira: “De acordo com dois principais autores que teorizaram a existência de uma estrutura social real, Èmile Durkheim (1893/1967) e Hans Kelsen (1934), nós podemos demonstrar que algo é governado por regras (prescritivas) apenas se há uma sanção. Podemos definir isso como o axioma de Durkheim-Kelsen (DK). Há alguns teoremas que seguem o DK: 1. Nem todo o sistema regulado é um jogo (ex.: sistemas lega is não são jogos). (1.1) Um corolário é "regras podem ser necessárias, mas não são suficientes para a constituição de jogos". (2) Há muitos jogos que não se baseiam em regras (ex.: correr em uma floresta tentando pegar um amigo e todos os jogos Ilinx, Mimicry, e Paidia da fenomenologia de Caillois). Além disso, há muitos jogos que se baseiam em regras sem serem regulados (ex.: aqueles focados em transgredir as regras e aqueles focados em responder a questão “isso é um jogo ou não?”). Então, nem todos os jogos são regulados. Um corolário é "regras não são elementos suficientes e tampouco necessários para constituir jogos".
} 
jogador. Certamente, diferente do que ocorre em um jogo de tabuleiro como Banco Imobiliário ou Warhammer, em um jogo de computador os jogadores não seguem regras. $A$ fortiori, os jogadores não prescrevem regras para fazer os personagens agirem, como fazer o Mário pular sobre um muro.

Há em vez disso relações materiais (nem linguísticas nem simbólicas) entre os objetos na tela e o sujeito que está jogando. Desse ponto de vista, entidades da tela têm o mesmo status ontológico dos limites do software e do hardware: eles existem independente do sujeito que os está utilizando. Diferentemente de regras ou identidades (fictícias), que são objetos sociais, entidades de tela como a figura de Mario e suas plataformas são objetos físicos. 0 jogador precisa interagir com eles (plataformas e muros do Mario) como interage com entidades físicas (as plataformas e muros de uma casa real). Uma situação completamente diferente é interagir com uma fronteira do Estado que, como um direito proprietário ou a mecânica de um jogo de tabuleiro de Banco Imobiliário, é governada por regras. Até no caso de um muro e uma regra escrita em uma placa de rua compartilharem o mesmo propósito (não deixar as pessoas passarem), elas operam de formas muito diferentes. A obrigação imposta por uma regra escrita em uma placa de rua existe apenas se os sujeitos concedem validade a essa regra; enquanto o muro não precisa do consenso humano para ser uma fronteira intransponível. Objetos virtuais de jogos de computador existem mesmo que o sujeito não dê seu consenso, exatamente como artefatos materiais. A partir desse ponto de vista, um muro virtual é exatamente como um muro material: ambos não são objetos sociais, mas fatos brutos. Obviamente as entidades em tela dependem das instruções dadas pelo programador à máquina. Essas instruções tem uma estrutura que é aparentemente linguística: elas parecem regras. Mas elas não são, pois o aparelho não pode desobedecê-las, exatamente como não pode entender seu valor (SEARLE, 1980). Entidades em tela não são uma representação gráfica das regras, mas apenas objetos.

De qualquer maneira, estas são apenas discussões teóricas: precisamos olhar para casos concretos. Apenas alguns jogos de computador usam regras com propósitos lúdicos, e normalmente eles são transposições de jogos de tabuleiro. Considere Magic the Gathering, o jogo de cartas (GARFIELD, 1993): sua versão oficial para computador, nomeada Magic Online (Leaping Lizard Software, 2002), tem a característica de impor em modo automático os efeitos escritos nas cartas (ex.: o poder de "infringir três danos a uma criatura"). Assim sendo, a carta é a descrição de uma affordance objetiva, não uma prescrição de regra. De modo inverso, a versão eletrônica não oficial deste jogo, chamada Magic Workstation (Magi- 
Soft Development, 2002), requer que o jogador imponha manualmente os efeitos das cartas, o que permite a possibilidade de não fazer isso da maneira que as regras prescrevem. Em Magic Workstation o oponente deve monitorar cada operação, porque erros e trapaças estão sempre à espreita. Designers de jogos de computador poderiam descobrir um novo conjunto de gêneros de games: jogos baseados em regras podem ser implementados em novos horizontes dos games, porque atualmente eles não são ${ }^{10}$.

Temos que evitar reduzir jogos de computador a games governados por regras. Da mesma maneira poderíamos também reduzir jogos de Lego ou Barbie a jogos governados por regras. Há 800 anos atrás, William de Ockham, o avô da ciência moderna, escreveu "entia non sunt multiplicanda praeter necessitatem 11". 0 conceito de regra não é explicativo em si mesmo. De acordo com Tavinor (2009b, p. 90), "grande parte das coisas que não são games podem ser vistas como algoritmos". Tavinor se refere a affordances e regras como declarações linguísticas: ambas preexistem à agência do jogador e a afetam, mas de formas diferentes. Affordances são propriedades relacionais e objetivas, enquanto regras são poderes deônticos que os sujeitos atribuem a algumas funções-status.

Jesper Juul (2005, p. 34-36) estende o conceito de regra às affordances, porque as duas são orientadas a objetivos. Mas se você quer criar um jogo onde os pés não são utilizados para controlar a bola, você pode fazer isso de duas maneiras: prescrevendo uma regra que proíbe o uso dos pés (como no handball), ou você pode fazer isso construindo uma affordance que inibe o uso dos pés (como no futebol americano). Referenciando Juul, a affordance da bola oval seria a regra material que proíbe que se controle a bola usando os pés. A regra do handball é bem diferente da affordance do futebol americano, por conta dos diferentes efeitos no desenvolvimento do jogo e por conta de sua estrutura ontológica distinta. Certamente uma regra existe apenas na medida em que é concebida por alguém, enquanto uma affordance existe mesmo se não for concebida.

Objetos virtuais não são feitos de regras, mas de affordances. Designers e programadores não prescrevem regras nem a computadores nem a jogadores. Eles apenas criam affordances que usuários podem usar para jogar ou não.

\footnotetext{
10 Desde 2011, o ano original da publicação deste artigo, encontrei muitos jogos que introduziram a possibilidade de trapacear conjuntos de regras explícitas. Mas, novamente, normalmente são transposições de jogos de tabuleiro, e, acima de tudo, ainda são muito raros.

11 Nota da Tradutora: a frase, em latim no original, poderia ser traduzida como "entidades não devem multiplicar-se além do necessário".
} 


\section{Nós realmente precisamos da virtualidade?}

Regras não são vinculadas ao uso de artefatos como vassouras ou computadores. Para mover Mario na tela e pular sobre um muro virtual nós não seguimos regras, basta pressionar um botão. Saber qual botão pressionar não é uma regra: é apenas um conhecimento simples, como saber como mover as pernas para pular sobre um muro real.

Lidando com essa questão, Brey (2003, p. 5) considera que as entidades virtuais não são nem físicas nem fictícias, apenas manejáveis. No entanto, gerenciabilidade não distingue realmente entidades virtuais de físicas. Um equívoco típico do começo dos game studies, que em parte ainda reverbera hoje está ligado ao que é chamado de entidade "virtual". De um ponto de vista ontológico, não há diferença entre entidades na tela e fora dela: as primeiras existem da mesma forma que objetos físicos. Entidades virtuais são entidades físicas, um muro virtual é tão real quanto um muro material.

A divisão de mundos em real e virtual não parece ontologicamente adequada. Do ponto de vista ontológico, mundos poderiam ser definidos como dimensões de realidade totalmente separadas. Até os mundos externos e internos (mente) estão estritamente conectados. As propriedades de um "mundo" virtual não são apenas físicas, elas são implicadas também por significados psíquicos ou semióticos. Do ponto de vista ontológico, não há algo como "realidades" virtuais ou "mundos" virtuais (LEHDONVIRTA, 2009). Não há "mundos virtuais" separados pelo mundo real: há apenas uma realidade, composta por muitos nichos regionais, alguns físicos, outros psíquicos e outros sociais. A questão da virtualidade não tem peso nem ontológico nem existencial. Ademais, a noção de "mundo virtual" ou "ciberespaço" usada por autores como Heim $(1993 ; 1998)$ ou Koepsell (2005, p.40) não diz respeito a uma totalidade (o conceito central quando estamos falando sobre realidade como Heidegger (1990), Fink (1956; 1960) ou Axelos (1974) o fazem), mas apenas um contexto. Então o virtual não é uma propriedade objetiva, mas apenas um contexto cultural, uma estrutura que alguns grupos sociais atribuem a certos objetos e atividades, vinculando-os à ficção. Mundos são fechados em si mesmos, enquanto contextos estão sempre conectados a outros e definidos por sua diferença. Por conta disso, nós não podemos coerentemente nos referir a algo chamado ciberespaço, mas apenas a uma série de ciberlugares interconectados, constituídos de affordances objetivas e objetos sociais subjetivos. 
Um tipo particular de objeto "virtual" criou alguns problemas para os primeiros teóricos dos ambientes digitais: as cópias virtuais de objetos reais. Do ponto de vista ontológico, cópias são objetos carregados de significado semiótico, os signos icônicos de Peirce (1906), baseados nas affordances dos seus formatos: eles representam um objeto pela força de sua semelhança analógica e objetiva, mas eles não são objetos mais especiais que qualquer outra forma de representação. Um caso muito diferente, em vez disso, é o das representações (incluindo reproduções virtuais de objetos reais) que são interpretados como sendo fictícios, como vimos, conforme uma atividade intencional de faz-de-conta.

\section{Brinquedos ergódicos}

Apenas alguns jogos de computador fazem uso de regras, mas todos eles fazem uso de affordances: eles tem uma propriedade ergódica ${ }^{12}$, mais típica de ferramentas do que de textos. Os jogos de computadores, como cavalos de balanço, Lego e Barbie, são brinquedos ergódicos porque eles carregam em si algumas coordenadas de seus usos lúdicos. Como qualquer ferramenta, uma vassoura tem uma propriedade ergódica que leva o usuário a usála para limpar o chão: mas suas affordances permitem usá-la também como um cavalo (de uma forma lúdica), mesmo que essas affordances não peçam de uma forma explícita para serem “jogadas". A propriedade ergódica típica dos jogos de computador nos leva ao faz-deconta do que é sugerido por suas representações e a interagirmos com elas. Não é todo o meio que tem propriedades ergódicas que sugerem o faz-de-conta ou uma interação, por exemplo, jornais diários levam seus leitores a interpretações sérias, enquanto ferramentas de jardinagem e carros que não são completamente automáticos levam seus usuários a interagir sem envolver uma atividade de faz-de-conta.

As estruturas ergódicas de jogos de computador excluem algumas possibilidades oferecidas por jogos tradicionais. Por exemplo, Costikyan (2002) mostra que se você joga com uma Inteligência Artificial você não pode fazer o papel de um personagem como em um RPG tradicional. A IA requer a interação com interfaces pré-definidas e a ação conforme esquemas fixos: a interface do Kinect do Xbox 360 reconhece os movimentos do jogador, mas ela não pode reconhecê-los e interpretá-los como uma pessoa poderia. Há uma enorme diferença cognitiva entre reconhecer e interpretar: a IA pode reconhecer se eu mover meu 
braço sobre minha cabeça (ex.: dando ou subtraindo pontos à minha coleção), mas não pode realmente reconhecer se eu estou dançando ou não. Algumas mecânicas tradicionais de jogo são focadas em blefar, uma atividade que não é possível simular em uma modalidade single player contra a IA.

Diferentes modelos de interação entre jogador e jogos de computador levam a estruturar o jogo de diferentes maneiras. Há games como Tetris, que se apresentam como um conjunto de objetos para serem manipulados direta e simplificadamente; outros games, como Pac-Man ou Doom, são representações de mundos habitados por avatares do jogador; finalmente, games como SimCity ou Civilization que permitem manipular indiretamente uma série de objetos cujo significado não depende apenas da percepção do usuário, mas também da enciclopédia cultural dele. A identificação do jogador com uma entidade na tela nunca é detectável no primeiro tipo de jogo (realmente útil para se familiarizar com novos sistemas e interfaces), é relevante no segundo tipo, e rara no terceiro (normalmente endereçada a jogadores experientes) ${ }^{13}$. Como no xadrez (FESTINI, 1998), também nos jogos de computador os jogadores iniciantes e experientes não sentem identificação como o jogador normal sente, que certamente prefere jogos com um avatar que pode ser usado como um intermediário para a identidade. Então a identidade parece ser um elemento central para jogadores meio-termo: em vários jogos nós podemos reconhecer três diferentes níveis da identificação dos jogadores conforme o game progride (ex.: em Spore, de Will Wright).

De qualquer forma, apesar de jogos de computador serem considerados jogos ergódicos, jogadores podem mudar o uso das interfaces e affordances do jogo para jogarem de maneira diferente (ex.: machinima) ou parar de jogar para começar outras atividades em vez disso (ex.: trabalhar no Second Life). Nós sempre precisamos ter em mente que as affordances não restringem nosso campo de pesquisa apenas a propriedades objetivas: em cada objeto há muitas affordances, mas, como vimos, elas não são sempre exploradas pelo usuário. As affordances de um objeto não podem forçar um sujeito a jogar com ela: uma vassoura pode ser usada para limpar assim como para brincar. Talvez qualquer outro objeto ou situação ofereça affordances tanto para brincar quanto para agir seriamente com elas. Então um game não depende totalmente de affordances objetivas e nossa interação com brinquedos e jogos de computador pode ser lúdica ou não. Temos que lembrar que o jogo é um modo, um estado intencional referido a uma atividade, um objeto ou um contexto. Assim como há jogos que fazem uso de affordances físicas, como Lego e jogos de computador, há 
também aqueles que usam affordances sociais, como jogos de azar, apostas, e todos os jogos baseados em promessas. Mesmo nesses casos, contudo, affordances podem ser desconsideradas: jogadores podem trapacear.

\section{Bug ou característica?}

0 quebra-cabeças mais importante para um testador de games é entender se um fenômeno é um "bug ou característica". Um bug deve ser corrigido, uma característica não. É um problema que não pode ser resolvido nem taxonomicamente nem ontologicamente, porque não é possível encontrar uma diferença universal entre um bug e uma característica. Por exemplo, os desenvolvedores de games online ficariam felizes em ter uma ferramenta universal para distinguir comportamentos trapaceiros de exploração de bugs, mas eles precisam analisar caso a caso. Como a exploração de bugs, as outras formas de trapaça são bem discutidos por Mia Consalvo (2009), cujo trabalho neste tópico nos leva a entender que jogar para perder ou reconfigurar o teclado não são consideradas trapaças apenas por contingência cultural. Um fenômeno como a trapaça não está relacionado a parâmetros objetivos. A razão é que mudar uma regra para uma única ocorrência (como uma exceção) não é o bastante para que você sinta que está trapaceando porque a trapaça está relacionada a mentir para outros jogadores e a um comportamento "sujo" que está integrado ao contexto do jogo (caso contrário, você não tem a sensação de trapacear, mas apenas de jogar outro jogo, talvez um desregulativo - depois veremos o que isso significa). As ideias do jogador são centrais no fenômeno da trapaça que, para ser compreendido, precisa ser relacionado às razões que levam o jogador a trapacear: por exemplo, é muito diferente não poder agir seguindo as regras e não aceitar perder.

De acordo com Juul (2005), a maior diferença entre jogos e jogos de computador é que nestes últimos as regras não são direcionadas imediatamente ao jogador, sendo processadas pela calculadora. Assim, o jogador não pode quebrar o poder deôntico das regras, porque elas não são dirigidas a ele. Neste caminho, o jogador só pode trapacear hackeando o código, uma ação material. Contra essa interpretação, Kristine Jørgensen (2003, p. 44) afirmou que "em um jogo clássico como xadrez, os movimentos das peças são definidos a priori, mas é decisão dos jogadores movê-las de acordo com as regras. Em jogos de computador, por outro lado, quase nunca é possível trapacear contanto que o game esteja completamente programado". Certamente os cheat codes "não podem ser vistos como quebra de regras; 
trata-se mais de um método de evitar as regras agindo para além delas". Então Jørgensen conclui que "em jogos clássicos o jogador normalmente precisa aprender as regras, enquanto em jogos de computador o jogador não precisa aprender nenhuma regra. Poderia ser dito que as regras de jogos de computador são invisíveis comparadas a de outros jogos. O jogador, no entanto, precisa aprender as regras da interface de qualquer jogo de computador, e embora não seja equivalente às regras estruturais tradicionais dos jogos, a interface pode ser vista como uma característica formal que precisa ser aprendida antes de ser capaz de jogar corretamente. A interface então compele o jogador no sentido de definir quais ações são possíveis dentro do game" (JøRGENSEN, 2004, p. 45É importante notar que a forma de coagir o jogador utilizada por uma affordance maquínica (como o motor limitado de um carro) é realmente diferente da forma utilizada por uma regra (como o limite de velocidade das leis de trânsito). Assim como uma máquina não pode trapacear (um computador, um carro), um jogador utilizando a máquina não pode trapacear simplesmente se referindo a suas affordances.

Neste contexto é possível situar um problema recente dos game studies: o "gameplay emergente" pode ser baseado em regras como a trapaça, exploração, griefing, twinking ou farming ${ }^{14}$, mas nós vimos que os jogos de computador não operam pelas regras, mas sim por eventos determinísticos (relacionados ao jogo como objeto) ou pelas affordances Gibsonianas (relacionadas ao jogador como sujeito). Jogadores não podem escolher seguir ou não as regras, mas apenas utilizar as entidades na tela de uma forma ou de outra. 0 que é interessante é que um jogador trapaceiro atribui a função-status deôntica (que interpreta como uma regra) a algo que não é prescritivo em si mesmo. Gameplays emergentes como trapaça, griefing, farming, etc. são baseados em objetos sociais (regras) e não em objetos físicos (entidades na tela). Portanto, designers que estão produzindo jogos com gameplay emergente baseado em regras podem operar apenas de duas maneiras diferentes: a primeira, tradicional, requer olhar para a ontologia social que os jogadores têm antes de jogar (apesar de que em um jogo de computador normal não há regras a se seguir, a questão é a perspectiva cultural anterior que diz ao jogador o que é permitido e o que não é, por exemplo, alguns jogadores poderiam fazer de conta que os EULAs ou livretos de instruções constituem o livro de regras do jogo, mas outros jogadores poderiam não pensar dessa forma); a segunda maneira, inovadora, requer inserir as regras nas mecânicas centrais do

\footnotetext{
14 Nota da tradutora: as denominações de práticas usualmente designadas em inglês pelos jogadores brasileiros não foram traduzidas.
} 
jogo, como em jogos de tabuleiro de mesa. A ontologia social de Searle nos permite compreender quais tipos de atividades de jogo podem depender de regras.

\section{Novos tipos de jogadores?}

Para funcionarem, jogos de computador não pedem que os jogadores sigam regras. Mas o gameplay emergente não é especificamente projetado por programadores e pode ser simulados como a concordância com regras. Por exemplo, alguns jogadores pensam que eles precisam seguir "o espírito do game", como foi concebido pelos autores, ou pela comunidade que o joga, ou como o acordo de licenciamento de software prescreve. Entretanto, na perspectiva futura dos jogos de computador baseados em regras, podemos traçar quatro tipos de jogadores principais (alinhados à categorização ingênua de Bartle), que eu infiro entrelaçando as noções de regras constitutivas e regulativas de Searle (1995 [1969]) com as noções de jogar pela e com as regras de Benveniste (1947) (MOSCA, 2010):

logadores regulativos: eles moldam uma atividade de jogo anteriormente não regulada com um sistema de regras. Por exemplo, um criador de grupos em um MMORPG ou um organizador de torneio multiplayer são os típicos jogadores que dão regras a jogos que existiam antes de sua regulação.

Łogadores constitutivos: jogos constitutivos não podem ser jogados sem que se faça referência a um sistema de regras. Jogadores de games como Magic Workstation ou outras versões digitais de jogos de tabuleiro (como aqueles no website Brettspielwelt.de) ou simples jogos-por-e-mail são jogadores constitutivos típicos. Um tipo específico de gold farmer é um jogador constitutivo porque ele respeita o sistema governado por regras de trocas dentro do jogo. Assim, os jogadores que sentem que os EULAs, códigos do programa, ou formas normais de jogar são os manuais de regras do jogo, poderiam ser considerados como os jogadores constitutivos que jogam jogos de paciência.

Logadores desregulativos: um jogo desregulativo é um jogo transgressivo, que foca em "não seguir" certas regras. Hackers e griefers são os principais subtipos de jogadores desregulativos, porque eles focam em não seguir algumas prescrições sociais (que, por sua vez, não estão incorporadas em affordances mecânicas).

Jogadores desconstitutivos: um jogo desconstitutivo é focado em desconstruir o poder deôntico das regras. Em ambientes analógicos, os jogadores desconstitutivos são aquelas pessoas que gostam de fazer piadas ou sátiras. Normalmente, jogos de computador não 
incorporam poderes deônticos porque eles não prescrevem coisa alguma, mas algumas atividades de jogo para-textuais baseadas em jogos digitais empregam a desconstrução de alguns sistemas de meta-regras, por exemplo produtores de machinima e uma vasta variedade de atividades de trollagem podem ser dirigidas para desconstruir a ideologia e a sintática dos games.

\section{Conclusões}

Similarmente, podemos dizer que as teorias que explicam o fenômeno dos jogos ligando-o às regras podem ser caracterizadas em quatro tipos:

a) teorias constitutivas - para essas teorias, jogos, por meio das regras, constituem novas realidades;

b) teorias regulativas - para essas teorias, jogos, por meio das regras, dão uma nova ordem a uma realidade existente.

c) teorias desregulativas - para essas teorias, jogos subtraem ordem da realidade existente.

d) teorias desconstitutivas - para essas teorias, jogos desconstroem o poder deôntico dos sistemas de regras e da sociedade.

Contudo, a maioria das teorias de jogos de computador fazem confusão entre regras descritivas utilizadas para construir simulações, regras prescritivas (ausentes), e as instruções do código do programa, dificultando todo o processo teórico. Esse artigo pode ser em parte concebido como uma caixa de ferramenta para examinar o nó recente criado pelo debate entre a proceduralidade de Bogost (2006) e a antiproceduralidade de Sicart (2009), onde o segundo critica a abordagem determinista baseada nas regras. Meu lado negro me leva a pensar que Sicart está correto porque ele diz que as regras em jogos de computador não são uma força causal e que o estudo do sujeito deveria ser aprimorado. Meu lado positivo, ao contrário, me leva a pensar que a abordagem 000 (Ontologia Orientada a Objetos) de Bogost é realmente interessante, mas se quisermos olhar para as regras e não apenas para as affordances, precisamos da Ontologia Social de Searle, que poderíamos ver como uma ramificação da 000. Olhando amplamente para outro debate mítico (mais antigo e talvez que nunca tenha existido) nós podemos ver que o Narrativismo descreveu os games como textos a serem interpretados, enquanto a Ludologia investigou-os como sistemas formais autônomos de regras (ou affordances). Gonzalo Frasca (2003) (um ludologista) 
afirmou que nunca houve um contraste real entre narrativismo e ludologia, subordinando o primeiro ao segundo. Pessoalmente, eu penso que o debate entre Murray (1998) e Aarseth (2000) foi bem sintetizado por Juul (2005) quando ele disse que games são coisas objetivas em um plano algorítmico formal, enquanto histórias são coisas subjetivas no plano interpretativo. Outro ponto de vista interessante é o de Jenkins (2010), que descreveu games como combinações de narração e regras que podem oferecer interação.

No entanto, a partir do ponto de vista particular adotado neste artigo, todas essas abordagens são insatisfatórias porque elas subestimam o papel do sujeito se relacionando ao conteúdo. Juul pensa que a ludologia consiste em apoiar a ideia de que games deveriam ser entendidos em seus próprios termos, e ludologistas propuseram que o estudo dos games deveria se preocupar com a análise dos sistemas abstratos e formais que eles escrevem. Em outras palavras, o foco dos game studies deveria estar nas regras de um jogo, não nos elementos representativos, que são apenas incidentais. Concordando com Juul, Aarseth também pensa que as dimensões do corpo de Lara Croft, já analisadas até a morte por teóricos fílmicos e outros estudos culturais são irrelevantes para os jogadores, porque um corpo de aparência diferente não faria com que eles jogassem de maneira distinta: um jogador, de acordo com Aarseth, nem ao menos vê o corpo de Lara Croft, mas olha através dele, para aquilo que o avatar permite que o jogador faça. Na mesma direção, poderia ser argumentado que a figura 2D do Mario poderia ser colocada em Tomb Raider sem nenhuma consequência real para os jogadores. Mas no fim todos nós sabemos que o corpo de Lara Croft vendeu mais cópias de Tomb Raider do que qualquer mecânica do jogo. Esse tipo de afirmação é realmente chocante, pois seria como dizer que o estudo da literatura deveria ser apenas semiótico e não semântico. Tomadas literalmente, essas teorias produziriam apenas projetos vanguardistas ou maneiristas e obras sem interesse em conteúdos, emoções e valores.

Esse artigo está destinado a mostrar que se não quisermos analisar games como textos, também não poderemos analisá-los como sistemas de regras, porque normalmente não há regras nos jogos de computador. Atualmente, falta nos game studies um tipo de hermenêutica, uma estética de nível semântico, uma crítica que possa tornar explícitos os significados implícitos (e não apenas as estruturas sintáticas). Para fazer isso é necessário construir um corpus de games que deveriam ser fáceis de encontrar e jogar. Sem bibliotecas (gratuitas e/ou públicas) não há escolas literárias, sem igrejas cheias de afrescos não há comunidades de pintores, sem museus não há nem Winckelmann nem Schiller, sem essai 
cineforum não há nem Bazin nem nouvelle vague. Um grande problema dos jogos de computador é sua disponibilidade: máquinas evoluem rápido demais, os títulos perdem seu apelo de mercado em pouco tempo, e não há uma forma simples de encontrar e jogar os games mais importantes da história dos jogos de computador. Isso é um problema material, os videogames são o produto mais importante da cultura contemporânea, que combina materialismo e adoração de imagens: jogadores de videogame interagem com o nível material e simbólico das imagens, recapitulando as características de nossa cultura. Analisar videogames é, então, uma prioridade intelectual ampla, não apenas um sub-escopo da indústria. Há muitas teorias diferentes: o debate se encaixa diretamente na geração de cultura e de política. Por conta disso, é importante sempre produzir novas teorias, que possam aprimorar nossa compreensão e concepção da cultura de games.

\section{Referências}

AARSETH, Espen. Cybertext: Perspectives on Ergodic Literature. Baltimore: Hopkins University Press, 1997.

AARSETH, Espen. Allegories of Space: The Question of Spatiality in Computer Games. In Markku Eskelinen and Raine Koskimaa (eds.). Cybertext Yearbook 2000. Jyväskylä: University of Jyväskylä, 2000.

AXELOS, Kostas. Horizons du monde. Paris: Éd. de Minuit, 1974.

BARTLE, Richard. Designing Virtual Worlds. San Francisco: New Riders, 2003.

BATESON, Gregory. A Theory of Play and Fantasy: A Report on Theoretical Aspects of the Project for Study of the Role of Paradoxes of Abstractions in Communication. American Psychiatric Association: Psychiatric Research Reports, [s.l], n. 2, 1955.

BATESON, Gregory. The Message "This Is Play". Nova York: Josia Macy Jr. Foundation, 1956.

BAUDRILLARD, Jean. Simulacros e Simulação. Lisboa: Relógio d'Água, 1991.

BENVENISTE, Émile. Le Jeu Comme Structure. Paris: Deucalion, 2: 159-167, 1947

BREY, Pae. The social ontology of virtual environments. The American Journal of Economics And Sociology, [s.l], n. 1, 2003.

BOGOST, Ian. Unit Operations: An Approach to Videogame Criticism. Boston: Mit Press, 2006. 
COSTIKYAN, Greg. I Have No Words \& I Must Design: Toward a Critical Vocabulary for Games. In: OF COMPUTER GAMES AND DIGITAL CULTURES CONFERENCE, 2002, Tampere. Proceedings... . Tampere: Tampere University Press, 2002.

FERNANDEZ VARA, Clara. The tribulations of adventure games: Integrating story into simulation through performance. Atlanta: Georgia Institute of Technology, 2009.

CONSALVO, Mia. Cheating: Gaining Advantage in Videogames. Boston: MIT Press, 2007.

CONTE, Amedeo. Regole eidetico-costitutive. Nuova civiltà delle macchine, [s.l.], v. 3, n. 4, p. 26-33, 1985.

DETERDING, Sebastian. The game frame: Systemizing a Goffmanian approach to video game theory. In: DIGRA, 2009, Londres. Proceedings... . Londres: University Of London, 2009.

FESTINI, Wally; LICCIONE, Davide. Psicologia degli scacchi: Aspetti cognitivi, immaginativi e affettivi del gioco. Milão: Rusconi, 1998.

FINK, Eugen. Oase des Glücks: Gedanken zu einer Ontologie des Spiels. Friburgo: Alber, 1956.

FINK, Eeugen. Spiel als Weltsymbol. Stuttgart: Kohlhammer, 1960.

FRASCA, Gonzalo. Ludologists love stories, too. In: DIGRA, 2003, Utrecht. Proceedings... . Utrecht: 2003.

GALILEI, Galileu. 0 ensaiador. São Paulo: Nova Cultural, 2000 [1623].

GALLOWAY, Alexander. R. Gaming: Essays on Algorithmic Culture. Minneapolis: University of Minnesota Press, 2006.

GARDNER, Martin. Mathematical games: The fantastic combinations of John Conway's new solitaire game 'Life'. Scientific American, [s.l], n. 223, 1970.

GIBSON, James. The ecological approach to visual perception. Boston: Houghton Mifflin, 1979.

GOMBRICH, Ernst Hans. Meditations on a Hobby Horse. In: WHYTE, L.l. (Ed.). Aspects of Form: A Symposium on Form in Nature and Art. Londres: Lund Humpries, 1951.

GREENFIELD, Patricia. Mind and Media: The Effects of Television, Videogames and Computers. Cambridge: Harvard University Press, 1984.

HEIDEGGER, Martin. Welt als 'Spiel des Lebens'. Frankfurt: Klostermann, 1990.

HEIM, Michael. The Metaphysics of Virtual Reality. Oxford: OUP, 1993.

HEIM, Michael. Virtual Realism. Oxford: OUP, 1998. 
HUME, David. Tratado da Natureza Humana. Lisboa: FGC, 2001 [1739].

ISER, Wolfgang. 0 ato da leitura: uma teoria do efeito estético. São Paulo: Ed. 34, 1999 [1976].

JENKINS, Paul. First Person Shooter. Londres: Hern Books, 2010.

JUUL, Jesper. Half-Real: Video Games between Real Rules and Fictional Worlds. Boston: MIT Press, 2005.

JØRGENSEN, Kristine. Aporia \& Epiphany in Context: Computer Game Agency in Baldur's Gate II \& Heroes of Might \& Magic IV. 2003. Tese (Doutorado) -University Of Bergen, Bergen, 2003.

KOEPSELL, David. R. A Ontologia do ciberespaço: a filosofia, a lei e o futuro da propriedade intelectual. São Paulo: Madras, 2005.

LASTOWKA, Greg. Rules of play. Games And Culture, [s.l], v. 4, n. 4, 2009.

LAUREL, Brenda. Computers as Theatre. Boston: Addison-Wesley, 1991.

LEHDONVIRTA, Vili. Virtual Worlds Don't Exist: Questioning the Dichotomous Approach in MMO Studies. Game Studies, [s.l], v. 10, n. 1, 2010.

MOSCA, Ivan. Le regole del gioco: Perché la realtà sociale non è un sistema normativo. Rivista di Estetica, n. 43, p. 247-266. 2010.

MOSCA, Ivan. The Social Ontology of Digital Games. In. ANGELIDES, M.C.; AGIUS, H. (orgs) Handbook of digital games. [s.l]: Wiley-IEEE, 2014. p. 607-644.

MOSCA, Ivan. What is it like to be a player: The qualia revolution in game studies. Games And Culture, [s.l], v. 12, n. 6, 2017.

MURRAY, Janet. Hamlet on the Holodeck: The Future of Narrative in Cyberspace; Boston: MIT Press, 1998.

MYERS, David. Signs, Symbols, Games, and Play. Games And Culture, [s.l], v. 1, n. 1, 2006.

PEIRCE, Charles S. Prolegomena for an apology to pragmaticism. The Monist, Chicago, n. 16, p.492-546, 1906.

RAWLS, John. Two Concepts of Ruled. In: FREEMAN, S.. Collected papers. Cambridge: Harvard University Press, 1999.

REINACH, Adolf. Die apriorischen Grundlagen des bürgerlichen Rechtes. Jahrbuch Für Philosophie Und Phänomenologische Forschung, [s.l], v. 1, n. 2, p. 685-847, 1913.

SAGENG, John Richard. Gameness and Negotiable Consequences. In: THE PHILOSOPHY OF COMPUTER GAMES CONFERENCE, 2009, Oslo. Proceedings... . Oslo: 2009. 
SALEN, Katie; ZIMMERMAN, Eric. Regras do jogo: fundamentos do design de jogos. Vol.1. São Paulo: Blucher, 2012.

SEARLE, John. Expressão e significado: estudos da teoria dos atos da fala. São Paulo: Martins Fontes, 1995 [1969].

SEARLE, John. Minds, Brains, and Programs. Behavioral And Brain Sciences, [s.l], v. 3, n. 3, 1980.

SEARLE, John. The Construction of Social Reality. EUA: Free Press, 1995.

SEARLE, John. Making the social world. Oxford: OUP, 2010.

SICART, Miguel. Not to choose: designing ethical gameplay. In: MINDTREK CONFERENCE, 2009, Tampere. Proceedings... . Tampere: 2009.

SICART, Miguel. No More Homo Ludens: Designing for an Ethical Player. In: THE PHILOSOPHY OF GAMES CONFERENCE, 2009, Oslo. Proceedings.... . Oslo: 2009.

TAVINOR, Grant. Bioshock and the Art of Rapture. Philosophy And Literature, [s.l], v. 33, n. $1,2009$.

TAVINOR, Grant. The art of videogames. Hoboken: Wiley-Blackwell, 2009.

VOSSEN, Deborah P. The Nature and Classification of Games. Avante, [s.l], v. 10, n. 1, 2004.

WALTON, Kendall L. Fearing Fictions. The Journal Of Philosophy, [s.l], v. 75, n. 1, p.5-27, 1978.

WALTON, Kendall. L. Mimesis as Make-Believe: On the Foundations of the Representational Arts. Cambridge: Harvard University Press, 1990.

WITTGENSTEIN, Ludwig. Tratado lógico-filosófico: Investigações filosóficas. Lisboa: FGC, 1987.

ZNAMIEROWSKI, Czeslaw. Podstawowe pojecia teorji prawa. Poznan: Fiszer i Maiewski, Poznan, 1924.

\section{Referências Ludográficas e Filmográficas}

DARROW, Charles. Monopoly, [Boardgame], Parker Brothers, 1935

FINCHER, David. The game, [Film], USA, 1997

GARFIELD, Richard. Magic: the Gathering, [Boardgame], Wizards of the Coast, 1993 
LEAPING LIZARD SOFTWARE, Magic Online, [PC Computer, Online Game], Wizards of the Coast, 2002 (2008): played 13 january 2011

ROSEDALE, Phillip. Second Life, Linden Lab, [PC], 2003

MAGIE, Elizabeth. The Landlord's Game, [Boardgame], Economic Game Company, 1906

MAGI-SOFT DEVELOPMENT, Magic Workstation, [PC Computer, Online Game], Magi-Soft Development, 2002: played 12 january 2011

MIYAMOTO, Shigeru. Donkey Kong, [Arcade Cabinet], Nintendo, 1981

PRIESTLEY, Rick. et al. Warhammer Fantasy Battle, [Boardgame], Games Workshop, 1983

REAL RAILWAY, Sotetsu Line Simulator Online, [PC Computer, Online Game],

http://www.realrailway.com/en/sotetsu/simulator.html, jogado em 10 de março de 2011.

\title{
To be and not to be, that is the quest: ontology of rules in computer-based games
}

\begin{abstract}
This article intends to demonstrate that games cannot be analyzed as rule systems. The theoretical tools available in John Searle's Social Ontology Project can be applied to game studies, especially in the analysis of rules. According to Social Ontology, both rules and games can be defined as subject-dependent objects, but the process of their constitution is different. Most part of game studies scholars explain computer games as rule systems, but normally there are no rules in computer-based games. Computer players neither obey nor follow rules, and neither designers nor programmers prescribe rules: instead, they create affordances that users can use in order to play or not. Indeed, the constitution of a game depends on the way the players intend their activity, which requires a complete awareness and the freedom to define it as a game or not. Finally, the article provides a categorization of games that make use of rules (just few computer games are included), a categorization of players who make use of rules, and a categorization of the game theories that refer to rules.
\end{abstract}

\section{Keywords}

Rules. Social Ontology. Computer Games. Game Studies. 